\title{
Approaches to Reducing Animal Use for Acute Toxicity Testing: Retrospective Analyses of Pesticide Data
}

\author{
Judy Strickland ${ }^{1(\bowtie)}$, Michael W. Paris ${ }^{1}$, David Allen ${ }^{1}$, \\ and Warren Casey ${ }^{2}$ \\ ${ }^{1}$ ILS, P.O. Box 13501 Research Triangle Park, Charlotte, NC 27709, USA \\ strickl2@niehs.nih.gov \\ 2 National Toxicology Program Interagency Center for the Evaluation \\ of Alternative Toxicological Methods, National Institute of Environmental \\ Health Sciences, P.O. Box 12233 Research Triangle Park, \\ Charlotte, NC 27709, USA \\ warren.casey@nih.gov
}

\begin{abstract}
In this study, we considered whether acute oral toxicity hazard classifications for pesticide formulations and active ingredients (AIs) could be used to assign acute dermal toxicity hazard classifications using U.S. Environmental Protection Agency (EPA) and the United Nations Globally Harmonized System of Classification and Labelling of Chemicals (GHS) hazard categories. This retrospective analysis used highly curated acute toxicity data for 503 formulations and 297 AIs. Hazard classifications based on rat oral $\mathrm{LD}_{50}$ values were compared to hazard classifications based on rat dermal $\mathrm{LD}_{50}$ values for the same substance. The concordance of oral and dermal hazard classification was $62 \%$ for formulations and $64 \%$ for AIs using the EPA system and $71 \%$ for formulations and $55 \%$ for AIs using the GHS. Overprediction of dermal hazard was $38 \%$ for formulations and $32 \%$ for AIs using the EPA system and $28 \%$ for formulations and $41 \%$ for AIs using the GHS. Underprediction of dermal hazard was $1 \%$ for formulations and $3 \%$ for AIs using the EPA system and $1 \%$ for formulations and $3 \%$ for AIs using the GHS. While concordance overall was modest, the very low underprediction rates show that acute oral hazard categories are sufficiently protective for acute dermal hazard classification. Use of oral hazard data to also classify dermal hazard would obviate the need to perform acute dermal toxicity tests for classification and labeling and thereby reduce the number of animals used for acute systemic toxicity testing of pesticides.
\end{abstract}

Keywords: Acute toxicity $\cdot$ Dermal toxicity $\cdot$ Oral toxicity Hazard classification

Michael W. Paris - Retired

(C) The Author(s) 2019

H. Kojima et al. (Eds.): Alternatives to Animal Testing, pp. 37-49, 2019.

https://doi.org/10.1007/978-981-13-2447-5_5 


\section{Introduction}

Dermal exposure to chemicals can occur during routine handling of chemicals or during accidental spills. Dermal exposure can contribute considerably to the internal dose of users exposed to hazardous substances [4], and in particular is an important source of internal dose for occupational chemical exposures [1, 15, 26]. For some types of chemicals, such as pesticides, the dermal route can be the most important route of exposure [12]. Because of this, the industrial hygiene community develops specific notations for substances expected to present a toxic hazard via dermal absorption [5]. Regulatory agencies use data from acute oral and dermal toxicity tests to determine the potential systemic toxicity of chemicals and chemical products following oral ingestion and topical exposure to the skin, respectively. $\mathrm{LD}_{50}$ values from such tests, representing the dose expected to produce lethality in 50\% of the animals tested, are used to assign substances to oral and dermal hazard categories. The hazard categories are then used to assign product packaging labels to caution workers and consumers about poisoning potential.

Figures 1 and 2 show two systems for classifying substances for acute toxicity hazard. Figure 1 summarizes the hazard classification system used by the U.S. Environmental Protection Agency (EPA). EPA requires hazard labeling to be applied to pesticides with dermal or oral $\mathrm{LD}_{50}$ values less than or equal to $5000 \mathrm{mg} / \mathrm{kg}$ [8].

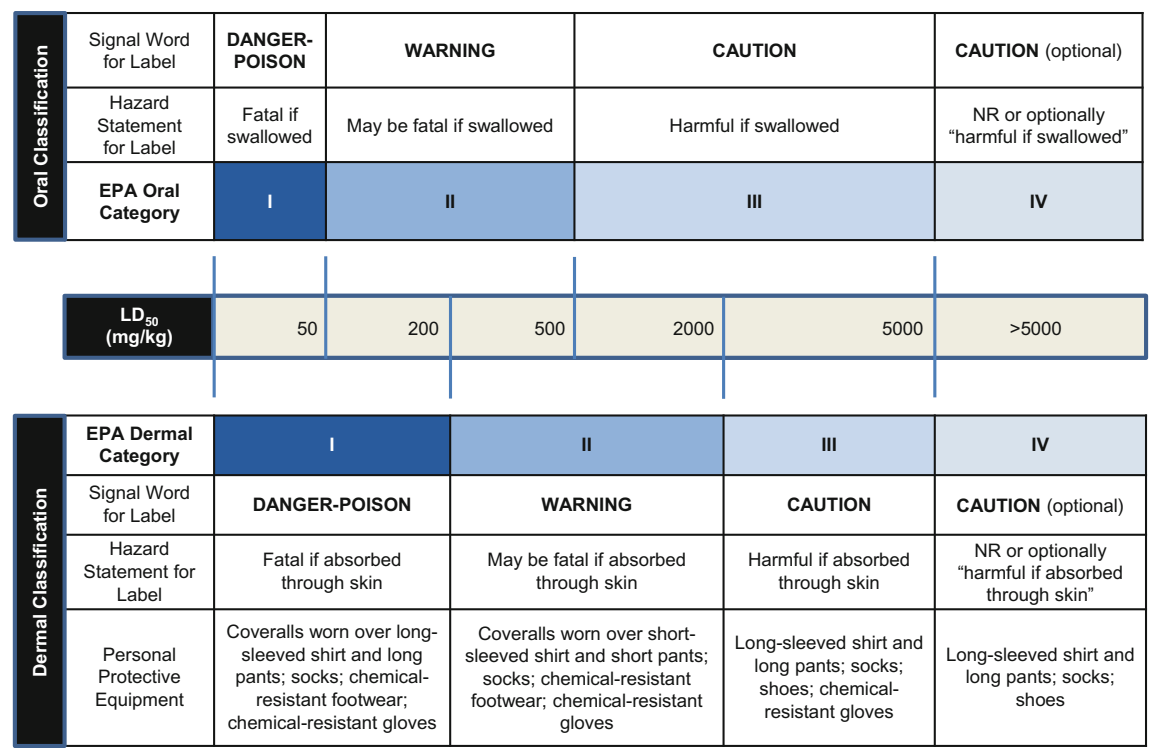

Fig. 1. EPA classification system for acute oral and dermal hazard according to the EPA Label Review Manual [8]. $N R$ not required. $\mathrm{LD}_{50}$ dose range is not to scale Chart is adapted from Seidle et al. [27] 
The EPA hazard classification system assigns a chemical to one of four oral and dermal hazard categories according to its relevant $\mathrm{LD}_{50}$ value, with each category associated with specific signal words and hazard statements that must be used in labeling that chemical. Dermal hazard categories are associated with specific recommendations for personal protective equipment to mitigate skin exposures.

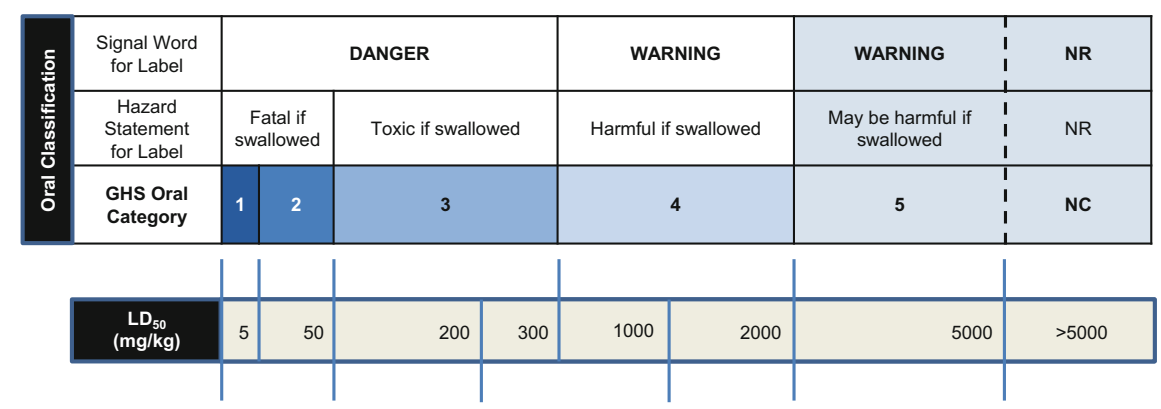

\begin{tabular}{|c|c|c|c|c|c|c|c|c|}
\hline 을 & $\begin{array}{l}\text { GHS Dermal } \\
\text { Category }\end{array}$ & 1 & 2 & 3 & 4 & 5 & $\begin{array}{l}\text { T } \\
\text { I } \\
\text { I }\end{array}$ & NC \\
\hline $\begin{array}{l}\frac{4}{4} \\
\frac{1}{0} \\
\frac{15}{0} \\
\end{array}$ & $\begin{array}{l}\text { Signal Word } \\
\text { for Label }\end{array}$ & \multicolumn{3}{|c|}{ DANGER } & WARNING & WARNING & I & NC \\
\hline 홍 & $\begin{array}{l}\text { Hazard } \\
\text { Statement } \\
\text { for Label }\end{array}$ & \multicolumn{2}{|c|}{ Fatal in contact with skin } & $\begin{array}{l}\text { Toxic in contact } \\
\text { with skin }\end{array}$ & $\begin{array}{l}\text { Harmful in } \\
\text { contact with } \\
\text { skin }\end{array}$ & $\begin{array}{l}\text { May be harmful in } \\
\text { contact with skin }\end{array}$ & $\begin{array}{l}\text { I } \\
\text { I }\end{array}$ & NR \\
\hline
\end{tabular}

Fig. 2. GHS classifications for acute oral and dermal hazard [30]. $N R$ not required, $N C$ not classified. $\mathrm{LD}_{50}$ dose range is not to scale. The shaded category is optional and was not used for the analyses herein. Chart is adapted from Seidle et al. [27]

Figure 2 provides the requirements for labeling according to the United Nations Globally Harmonized System of Classification and Labelling of Chemicals (GHS) [30]. The GHS was established with the goal of harmonizing rules and regulations for chemical handling and labeling at the national and international levels. The GHS has five hazard categories that are associated with specific signal words and hazard statements to be used on product labels for chemicals with $\mathrm{LD}_{50}$ values less than or equal to $5000 \mathrm{mg} / \mathrm{kg}$. However, Category 5, which provides for classification of chemicals having $\mathrm{LD}_{50}$ values greater than $2000 \mathrm{mg} / \mathrm{kg}$ but less than or equal to $5000 \mathrm{mg} / \mathrm{kg}$, is optional. When Category 5 is not used, the GHS hazard categories provide hazard notations for chemicals with $\mathrm{LD}_{50}$ values less than or equal to $2000 \mathrm{mg} / \mathrm{kg}$.

The GHS has been implemented in the European Union by Regulation No. 1272/2008 on classification, labelling and packaging of substances and mixtures, although the European Union does not use the optional Category 5 [11]. Some U.S. regulatory agencies have harmonized their classification systems with GHS. The U.S. Occupational Safety and Health Administration uses the same GHS categories as the European Union, omitting use of the optional Category 5 [25]. The U.S. Department of 
Transportation uses a packing group system that is consistent with GHS Categories 1 through 3 to determine appropriate packaging and labeling of poisonous materials during transport [3].

Acute toxicity tests are the most commonly conducted product safety tests worldwide [13]. These tests can require large numbers of animals, and the animals used may experience significant pain and distress. Test methods for acute dermal systemic toxicity are described in test guidelines issued by EPA and the Organisation for Economic Co-operation and Development (OECD). The current EPA test guideline [6] and the previous OECD test guideline [17] recommend using a minimum of 20 animals for the main test. A recently revised OECD test guideline adopted in late 2017 uses a stepwise procedure that requires less than 10 animals per test [24]. Acute oral systemic toxicity test guidelines were updated years ago to minimize the number of animals used [7, 19, 20, 22] and provide refinement by minimizing pain and distress [19]. Additionally, an OECD guidance document [23] provides information on using an in vitro test method to predict a starting dose, thereby further reducing animal use. Currently, acute oral tests can typically use five to nine animals for main tests and five to six animals for limit tests [18].

While significant reductions in animal use for acute systemic toxicity testing have been achieved, there is a great deal of interest, for both efficiency and ethical considerations, in further reducing the number of animals used for this purpose. If acute oral toxicity data were found to be sufficient to classify pesticides for both oral and dermal hazards, the acute dermal toxicity test would then be unnecessary, thereby reducing the number of animals used for acute systemic toxicity testing. This paper describes an evaluation to determine whether acute oral toxicity classifications for pesticide formulations and active ingredients (AIs) can be used in lieu of acute dermal toxicity data for dermal hazard classification and labeling.

\section{Materials and Methods}

We collected acute oral and dermal $\mathrm{LD}_{50}$ data for 503 pesticide formulations and 297 AIs. To eliminate the uncertainty associated with comparing results across species, we only used $\mathrm{LD}_{50}$ data from acute oral and dermal tests that used rats. We obtained these data from the following sources:

- EPA Data Evaluation Reports

- EPA Reregistration Eligibility Decision documents

- Study reports submitted to fulfill EPA regulatory requirements (provided by EPA)

- Two peer-reviewed publications on acute toxicity testing of chemicals $[2,16]$

- Two publicly available online toxicity databases:

a. Hazardous Substances Data Bank [31]

b. European Chemicals Agency database [10] 


\section{Data Quality Evaluation}

Data were evaluated for reliability using Klimisch categories [14]. Only $\mathrm{LD}_{50}$ data with a reliability score of 1 (reliable without restriction) or 2 (reliable with restrictions) were used for our analyses. The exception was data from Creton et al. [2]; this reference indicated that the data included were reliable, but did not specify the methods used to determine reliability.

\section{Categorization of Data}

We assigned oral and dermal hazard classifications to the 503 pesticide formulations and 297 AIs according to the EPA and GHS classification systems using the respective oral and dermal $\mathrm{LD}_{50}$ values. We adopted the implementation of GHS that does not use the optional Category 5. Thus, substances with $\mathrm{LD}_{50}$ values greater than $2000 \mathrm{mg} / \mathrm{kg}$ were unclassified. If more than one $\mathrm{LD}_{50}$ value was available for a substance (for example, if $\mathrm{LD}_{50}$ values were reported for male rats, female rats, and both sexes combined), we used the lowest (i.e., most toxic) $\mathrm{LD}_{50}$ value to categorize the substance. When an $\mathrm{LD}_{50}$ was listed as greater than a specific value (e.g., greater than 2000 $\mathrm{mg} / \mathrm{kg}$ ), it was assigned a value just above the specific value (i.e., $2001 \mathrm{mg} / \mathrm{kg}$ for the preceding example) to assign the hazard category.

\section{Analyses}

We calculated concordance, underprediction, and overprediction rates for the classification of dermal hazard on the basis of the oral hazard classification. In these calculations, we excluded 27 formulations and 64 AIs from EPA classification because of the uncertainty of their dermal hazard classifications. These substances were characterized on the basis of limit tests as having oral $\mathrm{LD}_{50}$ values greater than $5000 \mathrm{mg} / \mathrm{kg}$ and dermal $\mathrm{LD}_{50}$ values either greater than $2000 \mathrm{mg} / \mathrm{kg}$ or greater than $4000 \mathrm{mg} / \mathrm{kg}$. Although the oral hazard classifications for these substances were unequivocal, their dermal classifications could be either EPA dermal hazard Category III $\left(\mathrm{LD}_{50}\right.$ greater than $2000 \mathrm{mg} / \mathrm{kg}$ but less than or equal to $5000 \mathrm{mg} / \mathrm{kg}$ ) or Category IV ( $\mathrm{LD}_{50}$ greater than $5000 \mathrm{mg} / \mathrm{kg}$ ). Thus, an accurate comparison of oral and dermal hazard was not possible because the highest doses tested for the two routes were not the same. The resulting subsets of 476 formulations and 233 AIs were used for the EPA classification analyses. As noted previously, the GHS hazard classifications were determined with four hazard categories and a "not classified" category (i.e., $\mathrm{LD}_{50}$ greater than $2000 \mathrm{mg} / \mathrm{kg}$ ). No substances were excluded from the GHS classification analyses because a substance with a dermal $\mathrm{LD}_{50}$ greater than $2000 \mathrm{mg} / \mathrm{kg}$ is not classified, even if the $\mathrm{LD}_{50}$ is actually greater than $5000 \mathrm{mg} / \mathrm{kg}$. Thus, the full data sets of 503 formulations and 297 AIs were used for the GHS analyses. 


\section{Results}

\section{Distribution of Substances Among Hazard Categories}

Figure 3 shows that, according to both the EPA and GHS hazard classifications, formulations and AIs in this data set were much more likely to be toxic via the oral route than via the dermal route, and formulations were less toxic than AIs.

\section{EPA Hazard Categories}

The majority of the formulations in our data set (70\% [331/476]) were classified by the EPA system as Category IV for dermal hazard (dermal $\mathrm{LD}_{50}$ greater than $5000 \mathrm{mg} / \mathrm{kg}$ ). However, only $36 \%$ (173/476) of these substances were classified by the EPA system as Category IV for oral hazard (Fig. 3a). Similarly, 23\% (54/233) of the AIs were classified by the EPA system as Category IV for dermal hazard, but only $12 \%(29 / 233)$ of these substances were classified as Category IV for oral hazard (Fig. 3b).

The higher toxicity of the AIs is indicated by the lower proportion of AIs in the lowest toxicity categories, compared to the formulations. A higher proportion of formulations were classified by the EPA system as Category IV for oral hazard compared to the AIs (36\% [173/476] vs. 12\% [29/233]), and similarly, more formulations than AIs were classified as EPA Category IV for dermal hazard (70\% [331/476] vs. 23\% [54/233]) (compare Figs. 3a and b).

\section{GHS Hazard Categories}

Nearly all of the formulations in our data set (98\% [494/503]) were not classified by the GHS for dermal hazard (dermal $\mathrm{LD}_{50}$ greater than $2000 \mathrm{mg} / \mathrm{kg}$ ) (Fig. 3c). As for the EPA system, a lower proportion of these substances (71\% [355/503]) was not classified by GHS for oral hazard. Similarly, 86\% (255/297) of the AIs were not classified by GHS for dermal hazard, but only $51 \%$ (151/297) of these substances were not classified for oral hazard (Fig. 3d).

As with the EPA system, the AIs as a group were classified by GHS as more toxic than the formulations. A higher proportion of formulations were not classified for oral hazard by GHS compared to the AIs (71\% vs. 51\%), and similarly, more formulations than AIs were not classified by GHS for dermal hazard (98\% vs. 86\%) (compare Figs. 3c and d).

\section{Concordance of Oral and Dermal Hazard Classifications}

Figure 4 compares the concordance of EPA and GHS oral and dermal hazard classifications for formulations and AIs. The EPA classifications for dermal and oral hazard were concordant for 62\% (293/476) of the formulations (Fig. 4a) and 64\% (150/233) of 

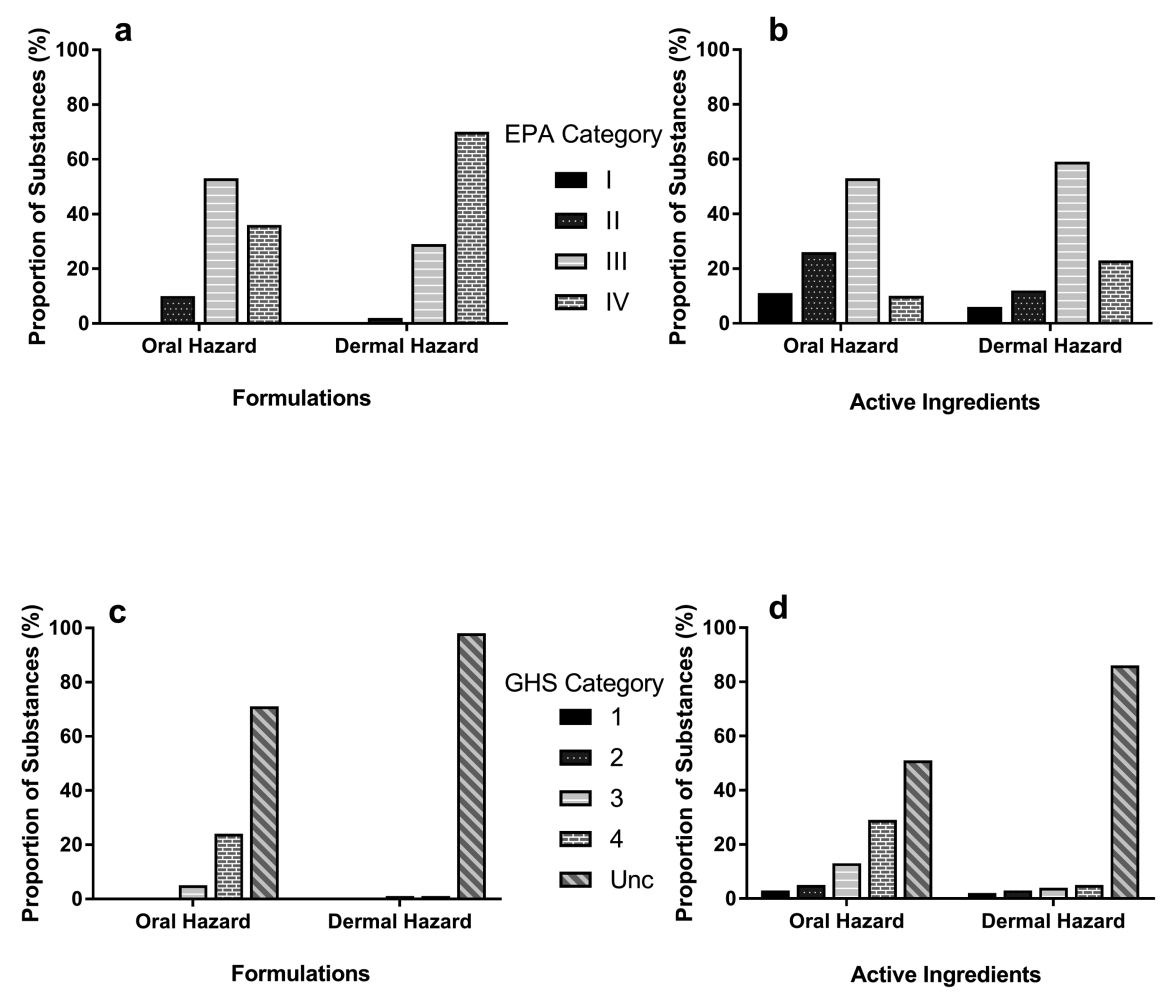

Fig. 3. Distribution of substances across EPA and GHS acute oral and dermal hazard categories. a) 476 formulations across EPA classifications b) 233 active ingredients across EPA classifications, c) 503 formulations across GHS classifications, d) 297 active ingredients across GHS classifications. UNC unclassified

the AIs (Fig. 4b). The EPA oral hazard classifications overpredicted dermal hazard for $38 \%(179 / 476)$ of the formulations and $32 \%(75 / 233)$ of the AIs. The EPA oral hazard classifications underpredicted dermal hazard for $1 \%$ (4/476) of the formulations and $3 \%$ (8/233) of the AIs.

The GHS classifications for dermal and oral hazard were concordant for $71 \%$ (358/503) of the formulations (Fig. 4c) and 55\% (164/297) of the AIs (Fig. 4d). The GHS oral hazard classifications overpredicted dermal hazard for $28 \%(142 / 503)$ of the formulations and $41 \%(123 / 297)$ of the AIs. The GHS oral hazard classifications underpredicted dermal hazard for $1 \%$ (3/503) of the formulations and $3 \%(10 / 297)$ of the AIs. 
a

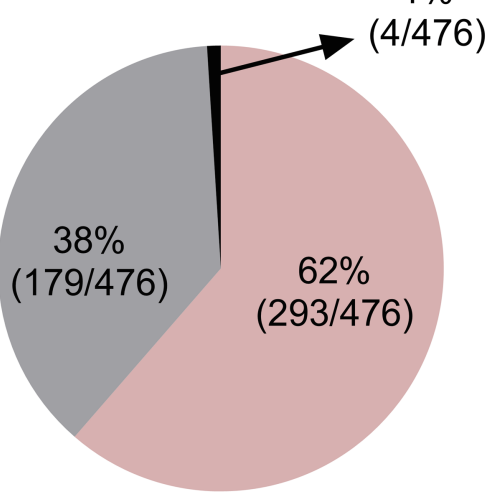

F - EPA Categories b $3 \%$

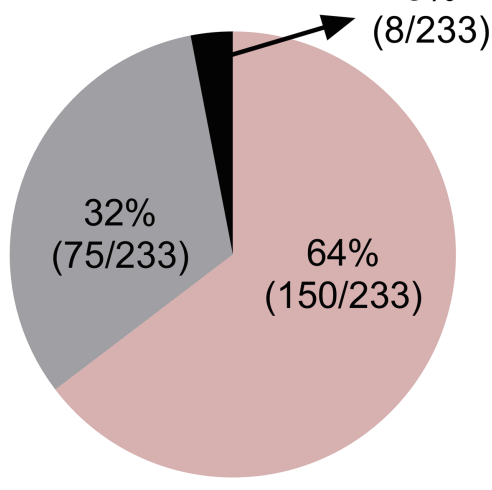

Al - EPA Categories

- Concordant

- Overpredicted

- Underpredicted

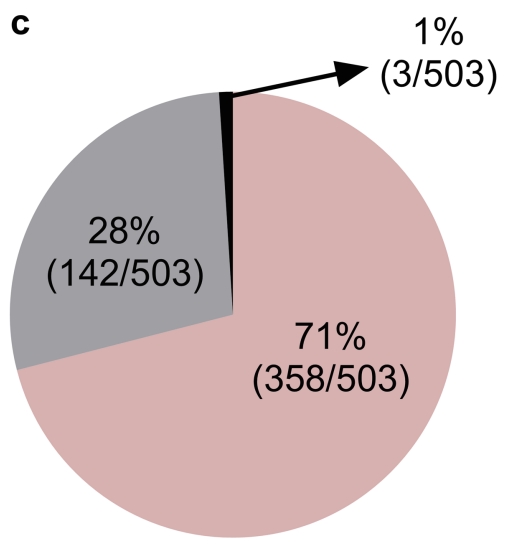

F - GHS Categories

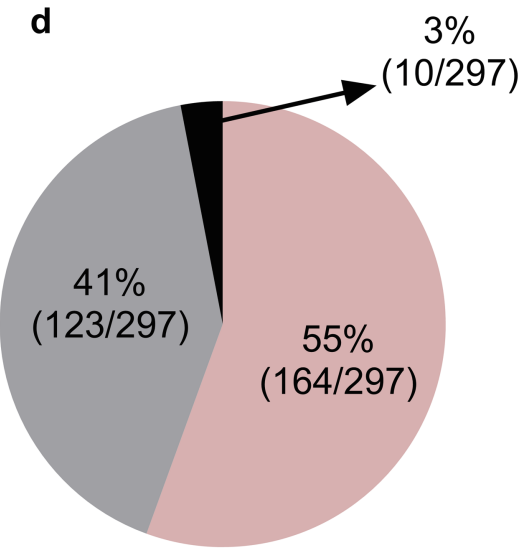

Al - GHS Categories

Fig. 4. Performance of oral hazard classification for predicting dermal hazard classification. Performance using the EPA classification system is shown with: a) 476 formulations and b) 233 active ingredients. Performance using the GHS classification system is shown with: c) 503 formulations and d) 297 active ingredients. $F$ formulations 


\section{Discussion}

Regulatory acceptance of any new alternative test method or approach requires that the new method or approach provide equivalent or better protection of human health [21, 28]. We conducted the current analysis of the use of acute oral hazard classification to classify substances for dermal hazard primarily to determine if there are instances where the acute dermal hazard is greater than the acute oral hazard. When the acute dermal toxicity hazard is greater than the acute oral toxicity hazard, the dermal hazard would be underpredicted by the oral hazard classification if that were used for dermal hazard classification. However, if such cases are rare or nonexistent, the use of oral hazard classification to predict dermal hazard would be at least as protective as using dermal $\mathrm{LD}_{50}$ data for this purpose because all of the predictions would either be concordant or would overpredict dermal hazard. Therefore, oral hazard categories could be used to determine dermal hazard classification without compromising public health, and product labeling could be based on the oral hazard without the need for an acute dermal systemic toxicity test.

Our analysis, which focused on the EPA hazard classification system and primarily included substances of interest to the EPA, found that using oral hazard classifications to predict dermal hazard classifications resulted in very few substances being underpredicted for dermal hazard. This is consistent with similar analyses conducted by other investigators [2, 16, 27]. Our reanalyses of these investigators' data, to the extent such data were available, provide further support for this conclusion.

Using a data set of 240 pesticide AIs, Creton et al. [2] showed that oral hazard underpredicted dermal hazard for only $0.8 \%$ (2/240) of the substances using the obsolete United Kingdom (UK) Chemicals (Hazard Information and Packaging for Supply) Regulations system [29]. The UK system was a four-category hazard classification system. Like GHS without the optional Category 5, the UK system did not classify substances with $\mathrm{LD}_{50}$ values greater than $2000 \mathrm{mg} / \mathrm{kg}$ as hazards, but the UK $\mathrm{LD}_{50}$ ranges for the other hazard categories were different from those used by the GHS. Because Creton et al. provided the dermal and oral $\mathrm{LD}_{50}$ data for the AIs, we were able to analyze them using the GHS and the EPA system. For our analysis of these data using the EPA system, we excluded substances with oral $\mathrm{LD}_{50}$ values greater than 5000 $\mathrm{mg} / \mathrm{kg}$ and dermal $\mathrm{LD}_{50}$ values greater than $2000 \mathrm{mg} / \mathrm{kg}$, as we did for our analysis. The underprediction rates for both EPA and GHS categories were very similar to those of our data set, which includes the Creton et al. data (Table 1).

In an analysis of a different set of 337 pesticide AIs using the same four GHS hazard categories we used, Seidle et al. [27] obtained concordance and underprediction rates similar to our AI analysis. Because this paper did not include $\mathrm{LD}_{50}$ data, we were not able to reanalyze their data to determine the concordance, underprediction, and overprediction rates for the classification of dermal hazard on the basis of the oral hazard classification using the EPA system.

Moore et al. [16] analyzed a broader data set of 335 substances, which included 110 pesticide AIs from Creton et al. [2] and 225 uncharacterized substances from the European Chemicals Agency database. Table 1 shows that concordance achieved by Moore et al. using GHS was much lower than ours and those of the other studies, and 
that their underprediction rates were higher. Our dataset consisted of only pesticide formulations and AIs. The higher underprediction and overprediction rates and lower concordance for the Moore et al. analysis could be due to inclusion of the uncharacterized substances, which comprised approximately $67 \%$ of their database. Again, because this paper did not include $\mathrm{LD}_{50}$ data, we were not able to reanalyze this data set to determine concordance using the EPA classification system.

While underprediction of dermal hazard would pose a clear danger to users, overprediction of dermal hazard is also undesirable, as overuse of stringent hazard warnings has a desensitizing effect, ultimately causing users to disregard them. The categorization approaches for our data sets showed that dermal hazard might be overpredicted by the oral hazard classification for $38 \%$ (179/476) of formulations using the EPA system and 28\% (142/503) of formulations using the GHS (Fig. 4a, c). Similarly, rates for overprediction of dermal hazard for AIs were $32 \%$ (75/233) with the EPA system and 41\% (123/297) with GHS (Fig. 4b, d).

The consequences of underprediction are more severe. Underprediction of dermal hazard could lead to warning labels and protective equipment recommendations inadequate to protect exposed persons, resulting in increased public health risk. Underprediction of dermal hazard would also affect the caution and care with which users handle consumer products. However, because dermal hazard classifications for only a small proportion of formulations (1\%) and AIs (3\%) in our dataset were underpredicted by using oral hazard data, our analyses suggest that acute oral hazard would provide appropriate recommendations for personal protective equipment for all but a small number of substances. If acute oral hazard were used to predict acute dermal hazard, animal testing for acute dermal toxicity would be necessary for few substances.

Our analyses, along with the others discussed here, indicate that it may be feasible to greatly reduce the use of animals for acute dermal toxicity testing of pesticide formulations and AIs. Based on the EPA acute dermal toxicity test guideline [6], waiving the dermal acute toxicity test and using oral hazard classification to assign dermal hazard classification would reduce the number of animals by 10 animals per pesticide for a limit test and 20 animals per pesticide for a main test.

EPA has used an analysis similar to ours to support guidance for waiving all acute dermal $\mathrm{LD}_{50}$ studies for pesticide formulations when acute oral $\mathrm{LD}_{50}$ studies are available [9]. Because EPA receives hundreds of acute dermal submissions for formulations each year, this development has the potential to reduce animal use significantly for acute toxicity testing. Although EPA has not waived the dermal test requirement for AIs, the waiver for formulations has a much larger impact on animal savings because the vast majority of new data submissions support registrations for formulations rather than AIs.

Future efforts to further reduce animal use for acute toxicity testing of pesticide formulations and AIs should be directed towards developing approaches to identify the small number of substances that might be underpredicted by acute oral toxicity testing before dermal tests are performed. In silico investigations of route-specific bioavailability could assist in identifying those substances. For substances that are likely to be 
Table 1. Comparison of oral and dermal hazard concordance analyses

\begin{tabular}{l|l|l|l|l}
\hline \multirow{2}{*}{$\begin{array}{l}\text { Oral-dermal hazard } \\
\text { comparison }\end{array}$} & \multicolumn{4}{|l}{ Analysis } \\
\cline { 2 - 5 } & $\begin{array}{l}\text { Current } \\
\text { analysis }\end{array}$ & $\begin{array}{l}\text { Creton et al. } \\
{[2]}\end{array}$ & $\begin{array}{l}\text { Seidle et al. } \\
{[27]}\end{array}$ & $\begin{array}{l}\text { Moore et al. } \\
{[16]}\end{array}$ \\
\hline GHS concordance & $\begin{array}{l}55 \% \\
(164 / 297)\end{array}$ & $\begin{array}{l}40 \% \\
(96 / 240)\end{array}$ & $\begin{array}{l}54 \% \\
(183 / 337)\end{array}$ & $\begin{array}{l}17 \% \\
(56 / 335)\end{array}$ \\
\hline $\begin{array}{l}\text { GHS underprediction } \\
\text { rate }\end{array}$ & $3 \%(10 / 297)$ & $4 \%(10 / 240)$ & $2 \%(6 / 337)$ & $7 \%(24 / 335)$ \\
\hline EPA concordance & $\begin{array}{l}64 \% \\
(150 / 233)\end{array}$ & $\begin{array}{l}64 \% \\
(116 / 182)\end{array}$ & NA & NA \\
\hline EPA underprediction rate & $3 \%(8 / 233)$ & $4 \%(7 / 182)$ & NA & NA \\
\hline
\end{tabular}

NA data not available "Current analysis" refers to the analysis described in this paper.

Concordance and underprediction rates for Creton et al. were calculated by us from data provided in their paper. Concordance and underprediction rates for the other papers were as reported; we were not able to calculate EPA concordance and underprediction rates for these data sets because $\mathrm{LD}_{50}$ data were not provided in the papers

more toxic dermally than orally and must be tested using the acute dermal toxicity test, the OECD test guideline has recently been revised to use a stepwise procedure that requires fewer than 10 animals [24].

\section{Disclaimer}

This article may be the work product of an employee or group of employees of NIEHS, $\mathrm{NIH}$, or other organizations. However, the statements, opinions or conclusions contained therein do not necessarily represent the statements, opinions, or conclusions of NIEHS, NIH, U.S. government, or other organizations. ILS staff do not represent NIEHS, the National Toxicology Program, or the official positions of any federal agency.

Acknowledgements. This project was funded in part with federal funds from the National Institute of Environmental Health Sciences (NIEHS), National Institutes of Health (NIH) under Contract No. HHSN273201500010C to ILS in support of the National Toxicology Program Interagency Center for the Evaluation of Alternative Toxicological Methods. The authors thank Catherine Sprankle, ILS, for editing the manuscript.

\section{References}

1. Boeniger MF, Lushniak BD (2000) Exposure and absorption of hazardous materials through the skin. Int J Occup Environ Med 6(2):148-150

2. Creton S, Dewhurst IC, Earl LK et al (2010) Acute toxicity testing of chemicals-Opportunities to avoid redundant testing and use alternative approaches. Crit Rev Toxicol 40 (1):50-83 
3. DOT (2011) Hazardous Materials Regulations, 49 CFR 173

4. Drexler H (1998) Assignment of skin notation for MAK values and its legal consequences in Germany. Int Arch Occup Environ Health 71(7):503-505

5. Drexler H (2003) Skin protection and percutaneous absorption of chemical hazards. Int Arch Occup Environ Health 76:359-361

6. EPA (1998) Health effects test guidelines: OPPTS 870.1200 - Acute Dermal Toxicity, EPA 712-C-98-192. U.S. Environmental Protection Agency, Washington, DC

7. EPA (2002) Health effects test guidelines: OPPTS 870.1100 - Acute Oral Toxicity, EPA 712-C-03-197. U.S. Environmental Protection Agency, Washington, DC

8. EPA (2016a) Label review manual, office of pesticide programs. U.S. Environmental Protection Agency, Washington, DC

9. EPA (2016b) Guidance for waiving acute dermal toxicity tests for pesticide formulations \& supporting retrospective analysis, office of pesticide programs. U.S. Environmental Protection Agency, Washington, DC

10. European Chemicals Agency (2017) Registered substances. https://echa.europa.eu/ information-on-chemicals/registered-substances Accessed 12 Dec 2017

11. European Union (2008) Regulation (EC) No. 1272/2008 of the European Parliament and of the Council of 16 December 2008 on classification, labelling and packaging of substances and mixtures, amending and repealing Directives 67/548/EEC and 1999/45/EC, and amending Regulation (EC) No. 1907/2006, Official Journal of the European Union, L353:11355

12. Grandjean P (1990) Skin penetration: hazardous chemicals at work. Taylor \& Francis, London

13. ICCVAM (2008) The NICEATM-ICCVAM Five-Year Plan (2008-2012): a plan to advance alternative test methods of high scientific quality to protect and advance the health of people, animals and the environment, NIH Publication No. 08-6410, National Institute of Environmental Health Sciences, Research Triangle Park, NC

14. Klimisch HJ, Andreae M, Tillmann U (1997) A systematic approach for evaluating the quality of experimental toxicological and ecotoxicological data. Regul Toxicol Pharmacol 25 (1): $1-5$

15. Lavoue J, Milon A, Droz PO (2008) Comparison of indices proposed as criteria for assigning skin notation. Ann Occup Hyg 52(8):747-756

16. Moore NP, Andrew DJ, Bjerke DL et al (2013) Can acute dermal systemic toxicity tests be replaced with oral tests? A comparison of route-specific systemic toxicity and hazard classifications under the globally harmonized system of classification and labelling or chemicals (GHS). Regul Toxicol Pharmacol 66:30-37

17. OECD (1987) Test no. 402: acute dermal toxicity, in OECD guidelines for the testing of chemicals, Section 4. Health Effects, Organisation for Economic Co-operation and Development, Paris

18. OECD (2001) OECD series on testing and assessment number 24, Guidance document on acute oral toxicity testing, ENV/JM/MONO(2001)4. Organisation for Economic Cooperation and Development, Paris

19. OECD (2002a) Test no. 420: acute oral toxicity - fixed dose procedure, in OECD guidelines for the testing of chemicals, Section 4. Health Effects, Organisation for Economic Cooperation and Development, Paris

20. OECD (2002b) Test no. 423: acute oral toxicity - acute toxic class method, in OECD guidelines for the testing of chemicals, Section 4. Health Effects, Organisation for Economic Co-operation and Development, Paris 
21. OECD (2005) OECD series on testing and assessment number 34. Guidance document on the validation and international acceptance of new or updated test methods for hazard assessment, ENV/JM/MONO(2005)14. Organisation for Economic Co-operation and Development, Paris

22. OECD (2008) Test no. 425: acute oral toxicity: up-and-down-procedure, in OECD guidelines for the testing of chemicals, Section 4. Health Effects, Organisation for Economic Co-operation and Development, Paris

23. OECD (2010) OECD series on testing and assessment no. 129. Guidance document on using cytotoxicity tests to estimate starting doses for acute oral systemic toxicity tests, ENV/JM/MONO(2010)20. Organisation for Economic Co-operation and Development, Paris

24. OECD (2017) Test no. 402: acute dermal toxicity, in OECD guidelines for the testing of chemicals, Section 4. Health Effects, Organisation for Economic Co-operation and Development, Paris

25. OSHA (Occupational Safety and Health Administration) (2012) Occupational safety and health standards, toxic and hazardous substances. Health Hazard Criteria, 29 CFR 1910.1200 Appendix A

26. Sartorelli P, Ahlers HW, Cherrie JW et al (2010) The 2008 ICOH workshop on skin notation. La Medicina del Lavoro 101(1):3-8

27. Seidle T, Prieto P, Bulgheroni A (2011) Examining the regulatory value of multi-route mammalian acute systemic toxicity studies. Altex 28(2):95-101

28. Stokes WS, Schechtman LM (2008) Validation and regulatory acceptance of new, revised, and alternative toxicological methods. In: Hayes AW (ed) Principles and methods of toxicology, 5th edn. CRC Press, Boca Raton, pp 1103-1130

29. UK (2002) The chemicals (hazard information and packaging for supply) regulations 2002. http://www.legislation.gov.uk/uksi/2002/1689/contents/made. Accessed 11 July 2017

30. United Nations (2015) Globally harmonized system of classification and labelling of chemicals, $6^{\text {th }}$ revised edn. United Nations, New York

31. U.S. National Library of Medicine (2017) Hazardous substances data bank (HSDB). https:// toxnet.nlm.nih.gov/cgi-bin/sis/htmlgen?HSDB. Accessed 10 July 2017

Open Access This chapter is licensed under the terms of the Creative Commons Attribution 4.0 International License (http://creativecommons.org/licenses/by/4.0/), which permits use, sharing, adaptation, distribution and reproduction in any medium or format, as long as you give appropriate credit to the original author(s) and the source, provide a link to the Creative Commons licence and indicate if changes were made.

The images or other third party material in this chapter are included in the chapter's Creative Commons licence, unless indicated otherwise in a credit line to the material. If material is not included in the chapter's Creative Commons licence and your intended use is not permitted by statutory regulation or exceeds the permitted use, you will need to obtain permission directly from the copyright holder.

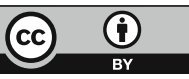

